\title{
Heptacoordinate Co(II) Catalyst for Light-driven Hydrogen Production in Fully Aqueous Medium"
}

\author{
Fiorella Lucarini ${ }^{\star *}$ and Albert Ruggi* \\ §SCS-Metrohm Award for the best oral presentation in Inorganic and Coordination Chemistry
}

\begin{abstract}
Photocatalytic hydrogen production is an appealing way to store solar energy as chemical fuel. The most studied molecular catalysts for $\mathrm{H}_{2}$ production are based on earth-abundant metals such as $\mathrm{Ni}$, Co and $\mathrm{Fe}$. Efforts have been recently focused on the design of Co complexes with distorted octahedral geometries induced by tetra- or pentapyridyl ligands. We synthesized a new Co(II) complex based on a hexapyridyl ligand that leads to the formation of an unusual heptacoordinate structure. In this paper, we review the characterization of the new catalyst and the optimization of the conditions for hydrogen evolution. The high activity reached after two hours of irradiation under visible light $(475 \mathrm{~nm})$ suggests that heptacoordinate cobalt complexes, not used so far in the field of light-driven hydrogen evolution, represent a promising alternative platform for the development of highly active and stable photocatalysts.
\end{abstract}

Keywords: Cobalt · Heptacoordinate complex $\cdot$ Hydrogen $\cdot$ Photocatalysis $\cdot$ Polypyridyl ligand

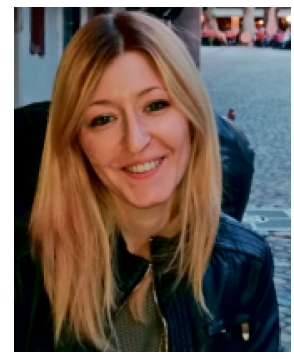

Fiorella Lucarini was born in Sezze (Italy). She obtained her Master's degree in Organic Chemistry Cum Laude at the University 'La Sapienza' of Rome in 2015. Then she started her PhD under the supervision of Dr. Albert Ruggi at the University of Fribourg where she is currently working on the development of catalysts for photochemical hydrogen production.
${ }^{*}$ Correspondence: F. Lucarini, Dr. A. Ruggi Department of Chemistry, University of Fribourg Chemin du Musée 9, $\mathrm{CH}$-1700 Fribourg

E-mail: fiorella.lucarini@unifr.ch, albert.ruggi@unifr.ch. \#An original report on this work has been previously published: F. Lucarini, M. Pastore, S. Vasylevskyi, M. Varisco, E. Solari, A. Crochet, K. M. Fromm, F. Zobi, A. Ruggi, Chem. Eur. J. 2017, 23, 6768-6771.

\section{Introduction}

The growing global pollution and the ever-increasing consumption of fossil fuels require the development of energetic systems based on renewable and sustainable sources. The light-driven reduction of water to produce hydrogen is a promising method to store and convert solar energy into chemical fuel. The production of $\mathrm{H}_{2}$ through water and light is part of an overall process called water splitting. ${ }^{[1]}$ The splitting of water involves two half-reactions: the oxidation of water to $\mathrm{O}_{2}$ and the reductions of protons to $\mathrm{H}_{2}$. Generally, due to the complexity of this process, the two half reactions are studied separately. ${ }^{[2]}$ In particular, three main components are required to produce $\mathrm{H}_{2}$ photocatalytically: a photosensitizer for light absorption and charge transfer, a sacrificial electron donor for the regeneration of the photosensitizer and a catalyst for proton reduction. Among the most studied photosensitizers, a predominant role is occupied by Ru-based complexes such as $\left[\mathrm{Ru}(\mathrm{bpy})_{3}\right]^{2+}$ (bpy $=2,2^{\prime}$-bipyridine) and its derivatives; concerning sacrificial species, electron donors such as ascorbic acid or trimethylamine have been used extensively. ${ }^{[3]}$ The design of catalysts represents a great and open challenge to achieve high activity and stability. Complexes based on cobalt and nickel have been the most studied catalysts because of their abundance and low price. ${ }^{[4]}$ Numerous groups including Zhao, Webster and co-workers and Alberto and co-work- ers have focused their attention on the synthesis of polypyridine cobalt complexes, which showed higher stability and activity with respect to the cobaloxime complexes used so far. ${ }^{[5]}$ A very important aspect, evidenced especially by Alberto and co-workers, is the relationship between geometry and catalytic activity. In fact, they pointed out that strongly distorted octahedral structures, induced by tetradentate or pentadentate polypyridine ligands, showed the best efficiency. ${ }^{[4 a, 5 e]}$ In our work, we designed a new hexadentate polypyridyl ligand to expand the study of the geometry-activity relationship. We obtained an unusual heptacoordinate $\mathrm{Co}$ (II) (less than $1 \%$ of the known structures $)^{[6]}$ and we investigated its characteristics and photocatalytic activity. The complex showed high catalytic activity for the production of $\mathrm{H}_{2}$ reaching a turnover number (TON) of $16300 \mathrm{~mol} \mathrm{H}_{2}$ (mol cat. $)^{-1}$ within $2 \mathrm{~h}$ under irradiation at 475 $\mathrm{nm}$ and in fully aqueous medium. ${ }^{[7]}$

\section{Synthesis and Characterization}

Scheme 1 shows the synthesis of the ligand obtained from N-Bis-(6-(2,2'bipyridyl)methyl)amine ${ }^{[8]}$ and 2-(bromomethyl)pyridine and the synthesis of $\mathbf{2}$ and 3, i.e. the complexes with $\mathrm{Cl}^{-}$and $\mathrm{PF}_{6}{ }^{-}$as counterion, respectively. Complex 2 is soluble in water and was used for photocatalytic reactions whilst complex $\mathbf{3}$ was prepared for electrochemical studies in $\mathrm{CH}_{3} \mathrm{CN}$. 
Scheme 1. Synthesis of the ligand 1 and complexes $\mathbf{2}$ and $\mathbf{3}$. Reproduced from ref. [7] with permission from John Wiley and Sons.

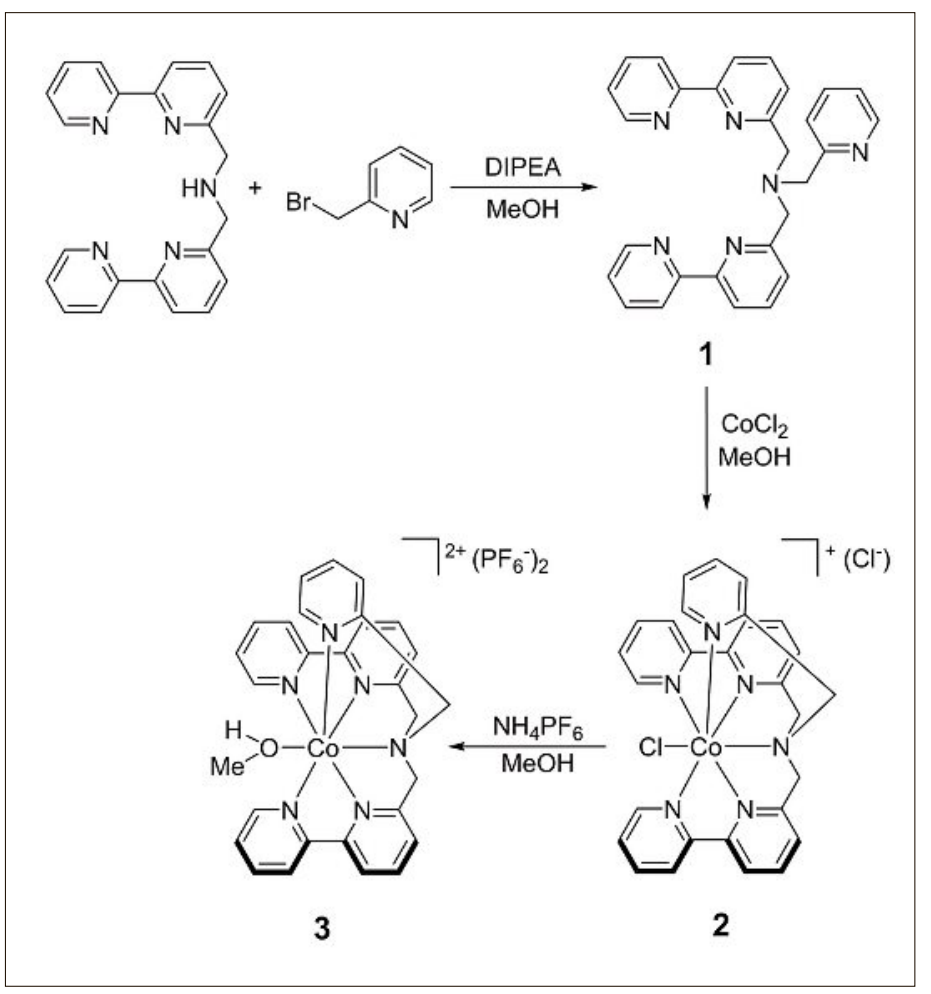

The crystal structures of compounds $\mathbf{2}$ and $\mathbf{3}$ show a heptacoordinate geometry which can be described as faced capped octahedrons with six positions occupied by the hexadentate ligand and one of the axial positions occupied by labile ligands as $\mathrm{Cl}^{-}$ or MeOH (Fig. 1). DFT studies (B3LYP/6$311 \mathrm{G}^{*}$ ) for the electronic structures of 2 and $\mathbf{3}$ point to a high-spin electronic configuration with high spin state $\left({ }^{4} \mathrm{Co}(\mathrm{II})\right)$ significantly lower in energy (ca. $0.7 \mathrm{eV})$ than the low spin state $\left({ }^{2} \mathrm{Co}(\mathrm{II})\right)$. In both cases for the high-spin complexes, we obtained a spin density of 2.8 electrons localized on the cobalt atom. These data were confirmed experimentally by the Evans method obtaining a magnetic moment $\mu_{\text {calcd }}=$ 5.3 BM which, according to literature, corresponds to a high-spin Co(II) system with three unpaired electrons. ${ }^{[9]}$ The agreement between computational results in the solid state and experimental data in solution suggest that no major structural changes take place upon complex dissolution.

The electrochemical experiments carried out in $\mathrm{CH}_{3} \mathrm{CN}$ for complex 3 exhibit two reversible reduction events at $-1.1 \mathrm{~V}$ and at $-1.61 \mathrm{~V}$ (all potentials vs. $\mathrm{Ag} / \mathrm{AgCl}$ ). We assigned the first signal to the $\mathrm{Co}(\mathrm{II}) /$ $\mathrm{Co}(\mathrm{I})$ reduction and the second signal to a ligand-centered process (Fig. 2). ${ }^{\text {10] }}$ Contrarily to all known Co polypyridine complexes, the oxidation wave for $\mathrm{Co}(\mathrm{III}) /$ $\mathrm{Co}$ (II) was not observed in the range of the solvent electrochemical window. ${ }^{[5 e]}$ Moreover, a first proof of the catalytic activity of the complex was evidenced by the evolutions of a catalytic wave upon addition of various amounts of acetic acid

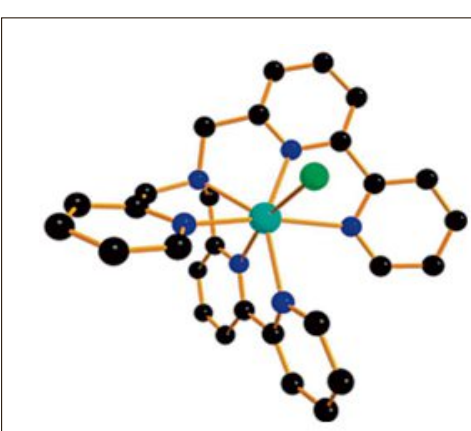

2

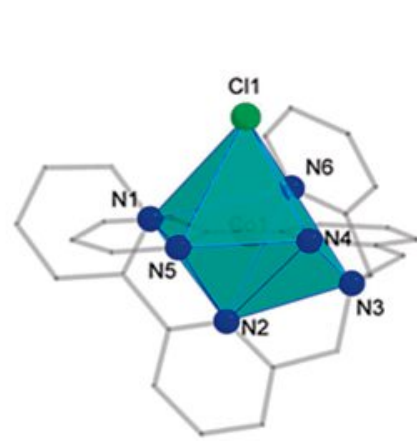

\section{Photocatalysis}

$\mathrm{H}_{2}$ evolution measurements were performed using a $25 \mathrm{~mL}$ water jacketed flask containing a buffer solution $(6 \mathrm{~mL}$ of $1 \mathrm{M}$ acetate buffer, $\mathrm{pH}=3-5.6$ ) with ascorbic acid $(0.1 \mathrm{M})$ as sacrificial electron donor, $\left[\mathrm{Ru}(\mathrm{bpy})_{3}\right] \mathrm{Cl}_{2}(0.5 \mathrm{mM})$ as photosensitizer and catalyst $2(0.1-10 \mu \mathrm{M})$. Periodically headspace sampling $(50 \mu \mathrm{L})$ was performed using a Hamilton sample lock syringe followed by injection into a GC Clarus 580 (Perkin Elmer). The photocatalytic experiments were executed at various catalyst concentrations, $\mathrm{pH}$ and temperature to feature the best conditions for hydrogen production. It was observed that TON increases decreasing the concentration of the catalysts (Fig. 3).

The highest TON of $16300( \pm 1600)$ mol $\mathrm{H}_{2}$ (mol cat. $)^{-1}$ is measured using a catalyst concentration of $0.1 \mu \mathrm{M}$ with a turnover frequency (TOF) of $5000( \pm 280)$ mol $\mathrm{H}_{2}$ (mol cat.) $)^{-1} \mathrm{~h}^{-1}$. Quantum yields of ca. $3 \%$ and $11 \%$ for $0.1 \mu \mathrm{M}$ and $10 \mu \mathrm{M}$ of catalyst were calculated using $\mathrm{Ru}(\mathrm{bpy})_{3} \mathrm{Cl}_{2}$ and 9,10-diphenylanthracene (DPA) as actinometer according to the operative procedure reported in ref. [12]. The formation of nanoparticles was excluded on the basis of dynamic light scattering measurements and mercury poisoning test. The dynamic light scattering showed no noticeable formation of nanoparticles larger than $2 \mathrm{~nm}$ and catalysis in the presence of $1 \mathrm{~mL} \mathrm{Hg}(0)$ did not show any change of activity, as expected for a homogeneous process. ${ }^{[13]}$

Moreover, we observed that systems with the same concentrations of photo-

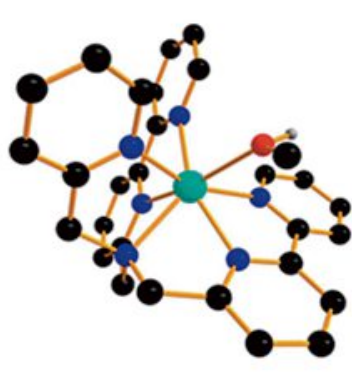

3

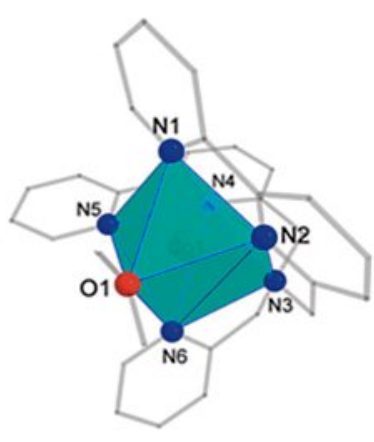

Fig. 1. Crystal structures of $\mathbf{2}$ and $\mathbf{3}$ (top) and labelling scheme of first coordination sphere (bottom). Color code: Co (turquoise), $\mathrm{N}$ (blue), $\mathrm{O}$ (red), C (black), Cl (green) and $\mathrm{H}$ (grey); counterions of $2\left(\mathrm{Cl}^{-}\right)$, of 3 [2(PF $\left.)_{6}-\right]$, methanol molecules and other $\mathrm{H}$ atoms have been omitted for clarity. Reproduced from ref. [7] with permission from John Wiley and Sons. 


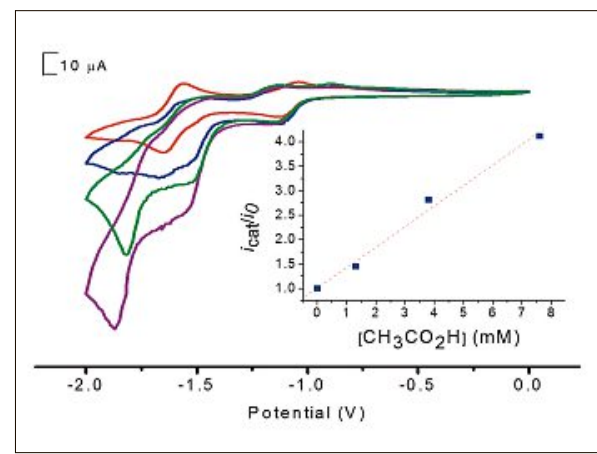

Fig. 2. Cyclic voltammograms of $4 \mathrm{mM}$ solutions of 3 in $\mathrm{CH}_{3} \mathrm{CN}, 0.1 \mathrm{M} \mathrm{TBAPF}_{6}$ at $0.1 \mathrm{~V} \mathrm{~s}^{-1}$ with 0 (red), 1.3 (blue), 4 (green), 8 (purple) $\mathrm{mM}$ of acetic acid. Inset: catalytic enhancement $\mathrm{i}_{\text {cat }} / \mathrm{i}_{0}$ (current in the catalytic wave over the current of the monoelectronic wave observed in the absence of acid) as a function of acid concentration. Glassy carbon working electrode, $\mathrm{Ag} / \mathrm{AgCl}(3.5 \mathrm{M} \mathrm{KCl})$ reference electrode and glassy carbon auxiliary electrode. Reproduced from ref. [7] with permission from John Wiley and Sons.

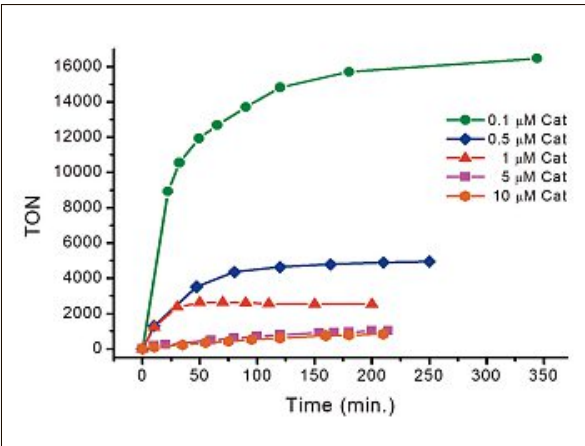

Fig. 3. Production of hydrogen over time in 1.0 $\mathrm{M}$ acetate buffer at $\mathrm{pH} 4.0$ with $0.1 \mathrm{M}$ ascorbic acid, $0.5 \mathrm{mM}\left[\mathrm{Ru}(\mathrm{bpy})_{3}\right]^{2+}$ and different concentrations of catalyst at $20^{\circ} \mathrm{C}$ with LED light $(475 \mathrm{~nm})$. Reproduced from ref. [7] with permission from John Wiley and Sons.

sensitizer $(20 \mathrm{mM})$ and catalyst $(20 \mathrm{mM})$ show a very low activity, indicating the necessity for the photocatalytic reaction of an excess of photosensitizer ( $c a .5000$ equivalents) with respect to the catalyst. Three independent experiments were performed to investigate the reasons of the end of hydrogen evolution observed after $c a$. 2 hours of irradiation. Addition of an equal starting amount of fresh $\left[\mathrm{Ru}(\mathrm{bpy})_{3}\right]^{2+}(0.5 \mathrm{mM})$ at the end of the catalysis re-established $19 \%$ of the $\mathrm{H}_{2}$ production upon irradiation (Fig. 4a). Conversely, a second cycle of irradiation after the addition of fresh ascorbic acid (0.1 M) generated only $10 \%$ of the initially formed $\mathrm{H}_{2}$ and the following injection of fresh catalyst $(0.5 \mu \mathrm{M})$ to this solution did not show any increase of produced $\mathrm{H}_{2}$ (Fig. $4 b)$. Finally, the concomitant addition of $\left[\mathrm{Ru}(\mathrm{bpy})_{3}\right]^{2+}(0.5 \mathrm{mM})$ and ascorbic acid (0.1M) gave $40 \%$ of hydrogen (Fig. $4 \mathrm{c}$ ). These data indicate that $\left[\mathrm{Ru}(\mathrm{bpy})_{3}\right]^{2+}$ and
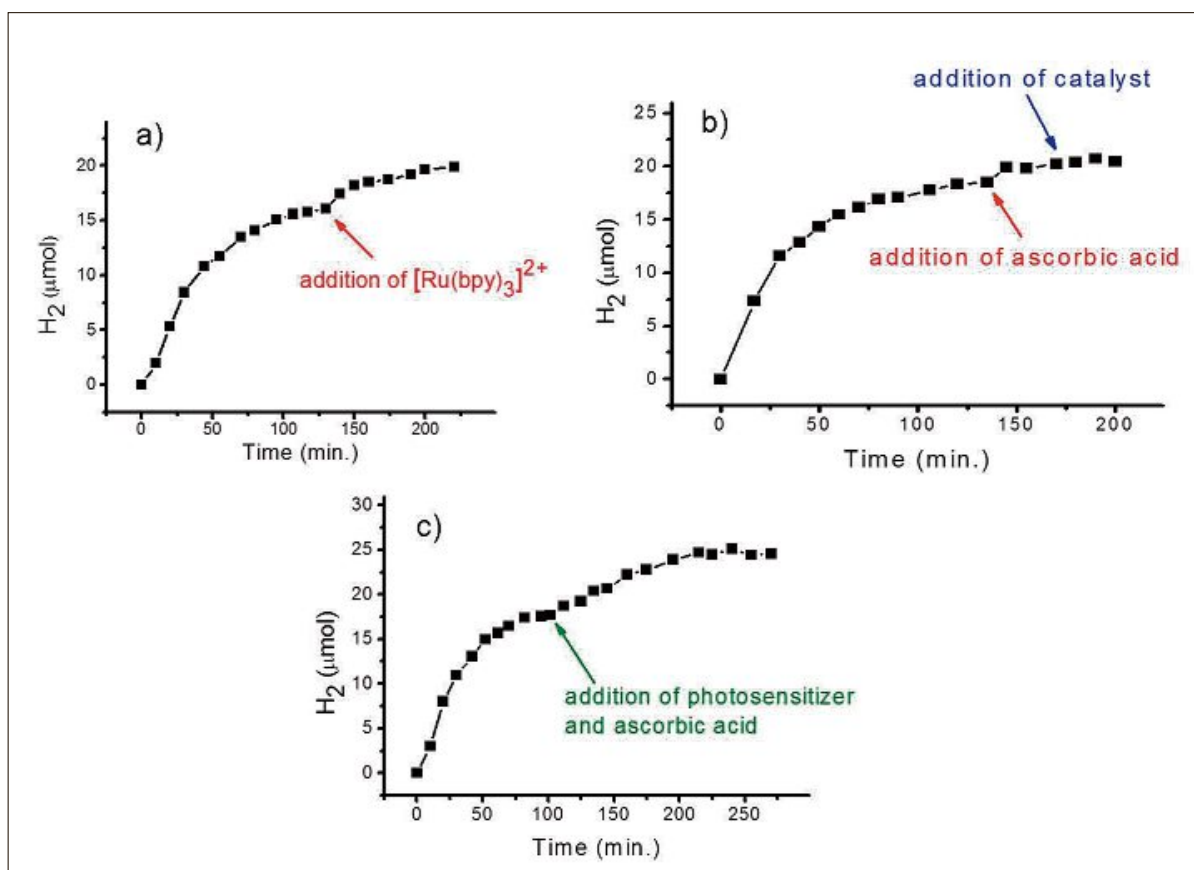

Fig. 4. Photocatalytic hydrogen production over time in $1.0 \mathrm{M}$ acetate buffer at $\mathrm{pH} 4.0$ with $0.1 \mathrm{M}$ ascorbic acid, $0.5 \mathrm{mM}\left[\mathrm{Ru}(\mathrm{bpy})_{3}\right]^{2+}$ and $0.5 \mu \mathrm{M}$ of catalyst at $20^{\circ} \mathrm{C}$ irradiated with LED light (475 $\mathrm{nm})$. a) The red arrow indicates addition of $0.5 \mathrm{mM}\left[\mathrm{Ru}(\mathrm{bpy})_{3}\right]^{2+}$. b) The red arrow indicates addition of $0.1 \mathrm{M}$ ascorbic acid and blue arrow indicates addition of $0.5 \mu \mathrm{M}$ catalyst. c) The green arrow indicates addition of $0.5 \mathrm{mM}\left[\mathrm{Ru}(\mathrm{bpy})_{3}\right]^{2+}$ and of $0.1 \mathrm{M}$ ascorbic acid. Reproduced from ref. [7] with permission from John Wiley and Sons.

ascorbic acid mainly affect the end of the catalysis.

Furthermore, HPLC studies of the reaction mixture before and after photocatalysis indicated that the catalyst remains stable during the $\mathrm{H}_{2}$ evolution. Blank experiments performed in the absence of $\left[\mathrm{Ru}(\mathrm{bpy})_{3}\right]^{2+}$, ascorbic acid or catalyst did not show any significant formation of $\mathrm{H}_{2}$, thus confirming the photocatalytic nature of the process.

The catalytic efficiency was observed to be $\mathrm{pH}$ - and temperature-dependent. The highest TON was reached at $\mathrm{pH}=4$ and a decrease of TON was observed upon temperature increase in the range of $5-30{ }^{\circ} \mathrm{C}$ with a concomitant increase of the TOF. ${ }^{[14]}$ This outcome is probably due to the detrimental effect of the temperature on the catalyst. Therefore, the operating temperature of $20{ }^{\circ} \mathrm{C}$ represents the best compromise between system stability and hydrogen evolution rate.

\section{Conclusions}

In conclusion, in our recent work we presented the first example of heptacoordinate cobalt catalyst for hydrogen production and we investigated the best conditions to improve its activity. We demonstrated that, under visible light irradiation in fully aqueous medium, this complex can efficiently catalyze the production of
$\mathrm{H}_{2}$ reaching a TON of $16300 \mathrm{~mol} \mathrm{H}_{2}$ (mol

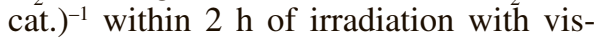
ible light $(475 \mathrm{~nm})$. Moreover, the oxidation potential of the couple $\mathrm{Co}(\mathrm{III}) / \mathrm{Co}$ (II) higher than $+2 \mathrm{~V}$ could enable the use of this complex in conjugated water splitting systems. This study suggests that heptacoordinate cobalt complexes represent a promising architecture, opening up new approaches for designing stable and active catalysts.

\section{Acknowledgements}

We thank the Swiss National Foundation (Grant FN 7359) for the generous financial support and the University of Fribourg.

Received: January 23, 2018

[1] N. S. Lewis, D. G. Nocera, Proc. Natl. Acad. Sci. USA 2006, 103,15729.

[2] V. Balzani, A. Credi, M. Venturi, ChemSusChem 2008, 1, 26.

[3] a) D. M. Arias-Rotondo, J. K. McCusker, Chem. Soc. Rev. 2016, 45, 5803; b) M. Guttentag, A. Rodenberg, R. Kopelent, B. Probst, C. Buchwalder, M. Brandstatter, P. Hamm, R. Alberto, Eur. J. Inorg. Chem. 2012, 59.

[4] a) V. Artero, M. Chavarot-Kerlidou, M. Fontecave, Angew. Chem. Int. Ed. 2011, 50, 7238; b) J. L. Dempsey, B. S. Brunschwig, J. R. Winkler, H. B. Gray, Acc. Chem. Res. 2009 , 42, 1995; c) P. W. Du, R. Eisenberg, Energy Environ. Sci. 2012, 5, 6012; d) U. J. Kilgore, J. A. S. Roberts, D. H. Pool, A. M. Appel, M. P. Stewart, M. R. DuBois, W. G. Dougherty, W. S. Kassel, R. M. Bullock, D. L. DuBois, J. Am. 
Chem. Soc. 2011, 133, 5861; e) P. A. Jacques, V. Artero, J. Pecaut, M. Fontecave, Proc. Natl. Acad. Sci. USA 2009, 106, 20627; f) A. Le Goff, V. Artero, B. Jousselme, P. D. Tran, N. Guillet, R. Metaye, A. Fihri, S. Palacin, M. Fontecave, Science 2009, 326, 1384.

[5] a) C. Bachmann, M. Guttentag, B. Spingler, R. Alberto, Inorg. Chem. 2013, 52, 6055; b) W. M. Singh, T. Baine, S. Kudo, S. L. Tian, X. A. N. Ma, H. Y. Zhou, N. J. DeYonker, T. C. Pham, J. C. Bollinger, D. L. Baker, B. Yan, C. E. Webster, X. Zhao, Angew. Chem. Int. Ed. 2012, 51, 5941; c) R. S. Khnayzer, V. S. Thoi, M. Nippe, A. E. King, J. W. Jurss, K. A. El Roz, J. R. Long, C. J. Chang, F. N. Castellano, Energy Environ. Sci. 2014, 7, 1477; d) D. Basu, S. Mazumder, X. T. Shi, H. Baydoun, J. Niklas, O. Poluektov, H. B. Schlegel, C. N. Verani, Angew. Chem. Int. Ed. 2015, 54, 2105; e) N. Queyriaux, R. T. Jane, J. Massin, V. Artero, M. Chavarot-Kerlidou, Coordin. Chem. Rev. 2015, 304, 3.
[6] M. Regueiro-Figueroa, L. M. P. Lima, V. Blanco, D. Esteban-Gomez, A. de Blas, T Rodriguez-Blas, R. Delgado, C. Platas-Iglesias, Inorg. Chem. 2014, 53, 12859.

[7] F. Lucarini, M. Pastore, S. Vasylevskyi, M. Varisco, E. Solari, A. Crochet, K. M. Fromm, F. Zobi, A. Ruggi, Chem. Eur. J. 2017, 23, 6768.

[8] M. D. Best, E. V. Anslyn, Chem. Eur. J. 2003, 9, 51.

[9] a) K. C. de Berg, K. J. Chapman, J. Chem. Educ. 2001, 78, 670; b) K. De Buysser, G. G. Herman, E. Bruneel, S. Hoste, I. Van Driessche, Chem Phys. 2005, 315, 286; c) B. F. B. R. Hoffmann, E. L. Muetterties, A. R. Rossi, Inorg. Chem. 1977, 16, 511

[10] a) M. Nippe, R. S. Khnayzer, J. A. Panetier, D. Z. Zee, B. S. Olaiya, M. Head-Gordon, C. J.Chang, F. N. Castellano, J. R. Long, Chem. Sci. 2013, 4, 3934; b) N. Elgrishi, M. B. Chambers, M. Fontecave, Chem. Sci. 2015, 6, 2522 .
[11] a) E. S. Rountree, B. D. McCarthy, T. T. Eisenhart, J. L. Dempsey, Inorg. Chem. 2014, 53, 9983; b) M. Razavet, V. Artero, M. Fontecave, Inorg. Chem. 2005, 44, 4786; c) A. M. Appel, M. L. Helm, ACS Catal. 2014, 4, 630; d) V. Fourmond, P. A. Jacques, M. Fontecave, V. Artero, Inorg. Chem. 2010, 49, 10338.

[12] S. P. Pitre, C. D. McTiernan, W. Vine, R. DiPucchio, M. Grenier, J. C. Scaiano, Sci. Rep. 2015, 5, 16397.

[13] W. K. C. Lo, C. E. Castillo, R. Gueret, J. Fortage, M. Rebarz, M. Sliwa, F. Thomas, C. J. McAdam, G. B. Jameson, D. A. McMorran, J. D. Crowley, M. N. Collomb, A. G. Blackman, Inorg. Chem. 2016, 55, 4564

[14] M. Natali, ACS Catal. 2017, 7, 1330. 